\title{
PEMBERDAYAAN MASYARAKAT DALAM PEMBANGUNAN INFRASTRUKTUR JALAN DI LINGKUNGAN KALATIN KELURAHAN LOWU UTARA
}

\author{
Marland Novel Ponowu \\ Caroline Betsi Diana Pakasi \\ Audrey Julia Maria Maweikere
}

\begin{tabular}{ll}
\hline Naskah diterima melalui Website Jurnal Ilmiah agrisosioekonomi@ unsrat.ac.id & $:$ Senin, 22 April 2019 \\
Disetujui diterbitkan & $:$ Kamis, 25 April 2019 \\
\hline
\end{tabular}

\begin{abstract}
This study aims to support community empowerment and increase the income of the community in road infrastructure development in the Kalatin Village, North Lowu Subdistrict, Ratahan District. Data collection is carried out for 3 months, from June 2018 to August 2018. The collected data is arranged quantitatively collected in the form of a table with sample of 30 respondents. This study uses primary data and secondary data. Primary data were obtained from interviews and questionnaires for the people living in the Kalatin Village and secondary data obtained from the relevant agencies. The results of the study show how community empowerment through cooperation to carry out the construction of road infrastructure in the Kalatin Village is well run by the Kalatin Village community to do various forms of participation in the form of work and food and beverages. The construction of road infrastructure in the Kalatin Village provides an increase in revenue of $14.29 \%$ - $650 \%$ or 6 times the revenue when the road has not been repaired. This is because the road infrastructure access to the marketing of commodities both inside and outside the Kalatin Village. ${ }^{\text {erprm* }}$
\end{abstract}

Keywords: community empowerment, road infrastructure, Kalatin Village

\begin{abstract}
ABSTRAK
Penelitian ini bertujuan untuk mengidentifikasi pemberdayaan dan tingkat pendapatan masyarakat akibat pembangunan infrastruktur jalan di Lingkungan Kalatin, Kelurahan Lowu Utara, Kecamatan Ratahan. Pengumpulan data dilakukan selama 3 bulan yaitu dari bulan Juni 2018 sampai dengan Agustus 2018. Data yang terkumpul disusun secara kuantitatif yang ditampilkan dalam bentuk tabel dengan jumlah sampel 30 responden. Penelitian ini menggunakan data primer dan data sekunder. Data primer yang diperoleh dari wawancara dan pengisian kuesioner terhadap masyarakat yang tinggal di Lingkungan Kalatin dan data sekunder yang diperoleh dari instansi terkait. Hasil penelitian menunjukkan bahwa pemberdayaan masyarakat melalui partisipasi masyarakat dalam bekerja sama untuk melaksanakan pembangunan infrastruktur jalan di Lingkungan Kalatin dikatakan berjalan dengan baik karena masyarakat Lingkungan Kalatin melakukan bentuk partisipasi berupa pelaksanaan dalam bentuk tenaga dan makanan dan minuman. Pembangunan infrastruktur jalan di Lingkungan Kalatin memberikan dampak peningkatan pendapatan sebesar 14,29\% - 650\% atau 6 kali lipat dari pendapatan pada saat jalan belum diperbaiki. Hal ini karena infrastruktur jalan mempermudah akses pemasaran hasil komoditi baik didalam maupun diluar daerah Lingkungan Kalatin. ${ }^{*}{ }^{\text {erprm* }}$
\end{abstract}

Kata kunci: pemberdayaan masyarakat, infrastruktur jalan, Lingkungan Kalatin 


\section{PENDAHULUAN}

\section{Latar Belakang}

Pemberdayaan masyarakat adalah upaya untuk mengembangkan kemandirian dan kesejahteraan masyarakat dengan meningkatkan pengetahuan, keterampilan, serta memanfaatkan sumber daya melalui penetapan kebijakan, dan pendampingan sesuai dengan prioritas kebutuhan masyarakat (Bumdes, 2017). Salah satu pemberdayaan masyarakat desa adalah pembangunan infrastruktur jalan karena dapat membantu masyarakat dalam melakukan kegiatan pertanian sebagai mata pencaharian untuk meningkatkan pendapatan petani (Oroh, 2014).

Di Lingkungan Kalatin, Kelurahaan Lowu Utara, Kecamatan Ratahan, Kabupaten Minahasa Tenggara telah dilakukan pembangunan infrastruktur jalan pada tahun 2010 melalui swadaya masyarakat, dilanjutkan dengan bantuan dari APBD (Anggaran Pendapatan dan Belanja Daerah) pada 2014 sampai selesai. Pembangunan infrastruktur jalan di Lingkungan Kalatin di buat sebagai akses jalan untuk masyarakat yang ada di sekitar hutan Lindung Gunung Manimporok, dimana sebagian besar masyarakat sekitar pendapatannya dari hasil bertani. Perlunya bentuk partisipasi yang diberikan masyarakat memberi pengaruh terhadap kelancaran pembangunan. Dalam hal ini kontribusi dalam bentuk apapun akan diterima, sehingga masyarakat akan merasa lebih bertanggung jawab untuk menjaga dan memanfaatkan dengan baik. Berdasarkan pada uraian latar belakang, maka penulis tertarik menemukan aspek-aspek yang terkait dengan partisipasi masyarakat dalam judul: "Pemberdayaan Masyarakat Dalam Pembangunan Infrastruktur Jalan Di Lingkungan Kalatin, Kelurahan Lowu Utara".

\section{Rumusan Masalah}

Berdasarkan latar belakang, maka masalah penelitian ini sebagai berikut: "Bagaimana pemberdayaan masyarakat dalam pembangunan infrastruktur jalan di Lingkungan Kalatin Kelurahan Lowu Utara Kecamatan Ratahan Kabupaten Minahasa Tenggara?".

\section{Tujuan Penelitian}

1. Mengidentifikasi pemberdayaan masyarakat dalam pembangunan infrastruktur jalan di Lingkungan Kalatin.

2. Mengidentifikasi tingkat pendapatan masyarakat dengan adanya pembangunan infrastruktur jalan di Lingkungan Kalatin.

\section{Manfaat Penelitian}

Penelitian ini diharapkan mampu
memberikan dampak positif terhadap
pemberdayaan masyarakat dalam pembangunan
infrastruktur jalan serta mengetahui pendapatan
masyarakat sehingga tidak hanya dapat
memberikan manfaat yang cukup besar bagi
pendapatan masyarakat, tetapi juga dapat
menambah motivasi masyarakat untuk terus
meningkatkan pemberdayaan Lingkungan Kalatin
Kelurahan Lowu Utara Kecamatan Ratahan
Kabupaten Minahasa Tenggara.

\section{METODE PENELITIAN}

\section{Waktu dan Tempat Penelitian}

Penelitian ini berlangsung selama 3 bulan yaitu dari bulan Juni sampai dengan Agustus 2018 mulai dari persiapan sampai dengan penyusunan laporan hasil penelitian. Penelitian dilakukan di Lingkungan Kalatin Kelurahan Lowu Utara Kecamatan Ratahan Kabupaten Minahasa Tenggara.

\section{Metode Pengumpulan Data}

Penelitian ini menggunakan data primer dan data sekunder. Data primer yang diperoleh dari wawancara dan pengisian kuesioner terhadap masyarakat yang tinggal di Lingkungan Kalatin Kelurahan Lowu Utara, Kecamatan Ratahan dan data sekunder yang diperoleh dari instansi terkait.

\section{Metode Pengambilan Sampel}

Metode pengambilan sampel dalam penelitian ini dilakukan secara Sengaja (Purposive Sampling), cara penarikan sampel yang dilakukan dengan memilih subjek berdasarkan kriteria spesifik yang ditetapkan peneliti. Berdasarkan tujuan jumlah sampel yang diambil sebanyak 30 responden yang berasal dari masyarakat yang tinggal di Lingkungan Kalatin Kelurahan Lowu Utara, Kecamatan Ratahan. 


\section{Konsep Pengukuran Variabel}

1. Pemberdayaan masyarakat merupakan bentuk pembangunan yang direncanakan, sesuai dengan potensi, masalah dan kebutuhan masyarakat. Pemberdayaan ditujukan agar masyarakat mampu berdaya, memiliki daya saing menuju kemandirian. Berdasarkan data yang dikumpulkan dalam penelitian ini menyangkut pemberdayaan masyarakat terutama peningkatan pendapatan sebagai dampak yang baik dengan pembangunan infrastruktur jalan dengan membandingkan keadaan tingkat pendapatan masyarakat pada saat jalan rusak dan setelah jalan menjadi baik sehingga dapat dilalui dengan lancer.

2. Partisipasi masyarakat merupakan keterlibatan dan atau keikutsertaan masyarakat secara sadar dalam proses pembangunan untuk mencapai suatu kondisi yang lebih baik dari sebelumnya. Berdasarkan data yang dikumpulkan dalam penelitian ini menyangkut hasil partisipasi masyarakat terhadap pembangunan infrastruktur jalan di lingkungan Kalatin.

\section{Metode Analisis Data}

Data yang terkumpul disusun secara kuantitatif yang ditampilkan dalam bentuk tabel dengan perhitungan persentase peningkatan pendapatan sebagai berikut:

$$
\text { Persentase Peningkatan Pendapatan }(\%)=\frac{\mathrm{B}-\mathrm{A}}{\mathrm{A}} \times 100 \%
$$

Ket:

$$
\begin{aligned}
\mathrm{A}= & \text { Pendapatan sebelum pembangunan } \\
& \text { infrastruktur jalan } \\
\mathrm{B}= & \text { Pendapatan setelah pembangunan } \\
& \text { infrastruktur jalan }
\end{aligned}
$$

\section{HASIL DAN PEMBAHASAN}

\section{Deskripsi Wilayah Penelitian}

Kalatin berada diwilayah administrasi Kelurahan Lowu Utara, Kecamatan Ratahan Kabupaten Minahasa Tenggara. Pemukiman Kampung Kalatin terpisah jauh yaitu sekitar 2,1 $\mathrm{km}$ dengan pemukiman kelurahan induk. Letak Lingkungan Kalatin berbatasan dengan kawasan hutan lindung. Menurut Kepala Lingkungan Kalatin, wilayah Lingkungan Kalatin sudah berada di luar dari wilayah hutan lindung.

Awalnya Lingkungan Kalatin merupakan tempat persembunyian dari masyarakat daerah Langowan dan Tompaso yang menghindari para penjajahan Belanda pada PD II yang datang ke daerah Minahasa. Nama Lingkungan Kalatin pertama kali adalah "Tinaledan". Kemudian masyarakat ini bersembunyi ke Lingkungan Kalatin dan setelah sekian lama mereka berada didesa tersebut maka akhirnya masyarakat inipun membuka lahan untuk berkebun dan kemudian menetap didaerah ini. Untuk menuju ke Lingkungan Kalatin akan melewati jalan utama yang kecil dan sempit.

Pada tahun 1998 Lingkungan Kalatin sudah menjadi desa persiapan karena alasan kecemburuan sosial masyarakat desa-desa sekitar yang tidak mengakui keberadaan dari masyarakat daerah ini. Oleh karena itu hingga saat penelitian ini dilaksananakan Lingkungan Kalatin belum disahkan mejadi desa.

Dengan batas-batas wilayah Lingkungan Kalatin adalah sebagai berikut :

1. Sebelah Utara berbatasan dengan Kepolisian Pangu.

2. Sebelah Timur berbatasan dengan Perkebunan Pangu.

3. Sebelah Selatan berbatasan dengan Perkebunan Rangkuli.

4. Sebelah Barat berbatasan dengan Wilayah Gunung Soputan.

Lingkungan Kalatin mempunyai iklim kemarau dan penghujan, ketinggian Lingkungan Kalatin kurang lebih $3.500 \mathrm{mdl}$, suhu udara tergolong dingin. Luas wilayah keseluruhan Lingkungan Kalatin adalah 550 ha dengan pembagian cakupan wilayah untuk lahan pemukiman 22 ha, lahan pertanian 350 ha, lahan pekuburan 0,75 ha dan hutan lindung 177,25 ha.

\section{Keadaan Penduduk}

Data penduduk Lingkungan Kalatin menunjukan pada tahun 2017 memiliki Jumlah penduduk sebanyak 403 jiwa. Jumlah penduduk laki-laki 216 jiwa dan perempuan 187 jiwa. Jumlah KK 118 jiwa. Tabel 1 menunjukan jumlah penduduk menurut laki-laki dan perempuan. 
Jumlah penduduk berjenis kelamin Lakilaki sebanyak 216 jiwa atau $(53,5 \%)$ dan jumlah pendudukan berjenis kelamin Perempuan sebanyak 187 jiwa atau (46,5\%). Bila dihitung menurut Rasio Jenis kelamin, RJK 115 (>100 jumlah penduduk laki-laki lebih banyak dibandingkan dengan jumlah penduduk perempuan, oleh karena itu potensi pertumbuhan penduduk secara alami di Lingkungan Kalatin menjadi lambat. Beda jika RJK <100 jumlah penduduk perempuan lebih banyak dibandingkan dngan jumlah penduduk laki-laki maka potensi pertumbuhan penduduk secara alami juga akan sangat cepat. Karena jika jumlah perempuan lebih banyak dan jumlah penduduk laki-laki lebih sedikit maka, pendudukan perempuan dapat menikah dengan laki-laki yang dari luar daerah.

\section{Umur Responden}

Umur dapat mempengaruhi kemampuan seseorang untuk bekerja secara fisik. Umur juga mempengaruhi produktivitas kerja dan peranannya dalam pengambilan keputusan dari berbagai alternatif pekerjaan yang dilakukan. Umur produktif antar 15 hingga 55 tahun. Jumlah responden disajikan pada Tabel 1.

Tabel 1. Jumlah Responden Menurut Kelompok Umur

\begin{tabular}{cccc}
\hline No & $\begin{array}{c}\text { Umur } \\
\text { (Tahun) }\end{array}$ & $\begin{array}{c}\text { Jumlah Responden } \\
\text { (Orang) }\end{array}$ & $\begin{array}{c}\text { Persentase } \\
(\%)\end{array}$ \\
\hline 1 & $20-29$ & 3 & 10,00 \\
2 & $30-39$ & 10 & 33,33 \\
3 & $40-49$ & 9 & 30,00 \\
4 & $50-59$ & 5 & 16,66 \\
5 & $60-64$ & 3 & 10,00 \\
\hline & Jumlah & 30 & 100,00 \\
\hline
\end{tabular}

Sumber : Diolah Dari Data Primer, 2018

Berdasarkan Tabel 1, dapat dilihat bahwa responden yang berada pada kisaran umur 20 29 tahun yaitu sebanyak 3 orang $(10,00 \%)$, kisaran umur antar 30 - 39 tahun sebanyak 10 orang $(33,33 \%)$, kisaran umur 40 - 49 tahun sebanyak 9 orang $(30,00 \%)$, kemudian kisaran umur 50 - 59 tahun sebanyak 5 orang $(16,66 \%)$, dan kisaran umur 60 - 64 tahun sebanyak 3 orang $(10,00 \%)$. Dari hal ini dapat dilihat bahwa, ternyata umur responden berpengaruh terhadap hasil pekerjaan dengan tingkat kesulitan untuk bertani dan tenaga yang mulai menurun.

\section{Tingkat Pendidikan}

Menurut teori human capital, kualitas sumber daya manusia selain ditentukan oleh tingkat kesehatan juga ditentukan oleh tingkat pendidikan. Pendidikan dipandang tidak hanya dapat menambah pengetahuan tetapi juga dapat meningkatkan keterampilan tenaga kerja sehingga akan meningkatkan produktivitas. Peningkatan produktivitas dapat meningkatkan pertumbuhan ekonomi dan meningkatkan penghasilan dan kesejahteraan penduduk. Selain keterampilan, tingkat pendidikan juga mempunyai pengaruh terhadap pola pikir masyarakat (Senoaji, 2011).

Secara umum masyarakat yang tinggal di Lingkungan Kalatin memiliki tingkat pendidikan yang rendah. Jumlah responden disajikan pada Tabel 2.

Tabel 2. Jumlah Responden Menurut Tingkat Pendidikan

\begin{tabular}{cccc}
\hline No & $\begin{array}{c}\text { Tingkat } \\
\text { Pendidikan }\end{array}$ & $\begin{array}{c}\text { Jumlah } \\
\text { Responden }\end{array}$ & $\begin{array}{c}\text { Persentase } \\
(\boldsymbol{\%})\end{array}$ \\
\hline 1 & SD & 18 & 60,00 \\
2 & SMP & 7 & 23,33 \\
3 & SMA/SMK & 4 & 13,33 \\
4 & Diploma/S1 & 1 & 3,33 \\
\hline & Jumlah & 30 & 100,00 \\
\hline
\end{tabular}

Sumber: Diolah Dari Data Primer, 2018

Tabel 2 menunjukkan bahwa respondenyang berpendidikan SD tertinggi sebanyak 18 orang $(60,00 \%)$, pendidikan SMP berjumlah 7 orang $(23,33 \%)$, kemudian pendidikan SMA/SMK sebanyak 4 orang $(13,33 \%)$, dan pendidikan Diploma/S1 terendah berjumlah 1 orang $(3,33 \%)$.

Tingkat pendidikan masyarakat di Lingkungan Kalatin tidak berpengaruh terhadap peningkatan pendapatan dilihat dari penghasilan terhadap pendidikan masyarakat. Hal ini karena masyarakat lebih memilih untuk menjadi petani dari pada mencari pekerjaan lain. Terdapat kecenderungan semakin banyak lahan, semakin banyak pula penghasilan yang didapatkan.

\section{Responden Menurut Jenis Mata Pencaharian}

Secara umum mata pencaharian penduduk Lingkungan Kalatin, diantaranya sebagai: Petani, Tukang, dan Wirausaha. Responden menurut jenis mata pencaharian Tabel 3. 
Tabel 3. Responden Menurut Jenis Mata Pencaharian

\begin{tabular}{llcc}
\hline No & \multicolumn{1}{c}{$\begin{array}{c}\text { Mata } \\
\text { Pencaharian }\end{array}$} & $\begin{array}{c}\text { Jumlah } \\
\text { Responden } \\
\text { (Orang) }\end{array}$ & $\begin{array}{c}\text { Persentase } \\
(\%)\end{array}$ \\
\hline 1 & Petani & 19 & 63,33 \\
2 & Tukang (pembuat & 4 & 13,33 \\
& rumah dari kayu) & 7 & 23,33 \\
3 & Wirausaha & 30 & 100,00 \\
\hline
\end{tabular}

Sumber : Diolah Dari Data Primer, 2018

Tabel 3 menunjukakan jenis mata pencaharian penduduk Lingkungan Kalatin diantaranya Petani 19 orang $(63,33 \%)$, kemudian Tukang 4 orang $(13,33 \%)$, dan Wirausaha 7 orang $(23,33 \%)$. Dari data tersebut mayoritas mata pencaharian masyarakat Lingkungan Kalatin adalah sebagai Petani karena banyaknya lahan perkebunan yang diambil hasil kebunnnya untuk dimanfaatkan atau dijual. Masyarakat Lingkungan Kalatin sangat membutuhkan infrastruktur jalan yang layak untuk digunakan karena sangat berpengaruh dengan mata pencaharian masyarakat sehingga masyarakat berinisiatif untuk membuat infrastruktur jalan dan memberikan hasil partisipasi masyarakat terhadap pembangunan infrastruktur jalan di Lingkungan Kalatin.

\section{Pemberdayaan Masyarakat Melalui Pembangunan Infrastruktur Jalan}

Pemberdayaan masyarakat adalah proses pembangunan di mana masyarakat berinisiatif untuk memulai proses kegiatan sosial untuk memperbaiki situasi dan kondisi diri sendiri. Pemberdayaan masyarakat hanya bisa terjadi apabila masyarakat itu sendiri ikut pula berpartisipasi.

Di Lingkungan Kalatin sendiri masyarakat berpartisipasi membangun infrastruktur jalan. Berdasarkan data yang dikumpulkan dalam penelitian ini menyangkut pemberdayaan masyarakat terutama peningkatan pendapatan sebagai dampak yang baik dengan pembangunan infrastruktur jalan dengan membandingkan keadaan tingkat pendapatan masyarakat pada saat jalan rusak dan setelah jalan menjadi baik sehingga dapat dilalui dengan lancar.

Prasarana jalan memiliki peran penting untuk mendukung aktifitas sosial dan pendapatan masyarakat. Peran tersebut dinikmati oleh masyarakat, baik sebagai penghasil, pedagang maupun konsumen. Produsen memanfaatkan jalan sebagai prasarana untuk mendapatkan bahan baku maupun pemasaran, distributor memanfaatkan jalan untuk mengangkut barang dagangannya ke pengecer maupun konsumen akhir, sementara konsumen mendapatkan keuntungan dari kualitas jalan yang baik dengan akses yang mudah.

Dengan adanya pembangunan infrastruktur jalan di Lingkungan Kalatin, masyarakat yang umumnya menjual hasil pertaniannya di daerah Lingkungan Kalatin sekarang bisa keluar daerah seperti di Tosuraya, Langowan, Pasar Karombasan hingga ke Sanger. Selain itu, Jalan di Lingkungan Kalatin bisa dilewati mobil yang lebih banyak, waktu tempuh yang lebih rendah, penjualan menjadi lebih banyak sehingga produksi masyarakat akan komoditinya semakin meningkat yang berdampak pada peningkatan pendapatan. Data peningkatan pendapatan sebelum dan sesudah pembangunan infrastruktur jalan dari sampel yang diambil dapat dilihat pada Tabel 4.

\begin{tabular}{|c|c|c|c|c|}
\hline & \multirow[b]{2}{*}{ Pekerjaan } & \multicolumn{2}{|c|}{ Pendapatan Perbulan } & \multirow{2}{*}{$\begin{array}{c}\text { Persentase } \\
\text { Kenaikan } \\
\text { Pendapatan }\end{array}$} \\
\hline & & $\begin{array}{c}\text { Sebelum } \\
\text { Pembangunan Jalan }\end{array}$ & $\begin{array}{c}\text { Sesudah } \\
\text { Pembangunan } \\
\text { Jalan }\end{array}$ & \\
\hline 1 & Tukang & Rp2.000.000 & Rp3.000.000 & 50,00 \\
\hline 2 & Tukang & Rp2.000.000 & Rp5.000.000 & 150,00 \\
\hline 3 & Tukang & Rp2.000.000 & Rp4.000.000 & 100,00 \\
\hline 4 & Tukang & Rp2.000.000 & Rp5 5.000 .000 & 150,00 \\
\hline 5 & Petani & Rp750.000 & Rp1.500.000 & 100,00 \\
\hline 6 & Petani & Rp1.500.000 & $\operatorname{Rp} 2.500 .000$ & 66,67 \\
\hline 7 & Petani & Rp500.000 & Rp2.000.000 & 300,00 \\
\hline 8 & Petani & Rp300.000 & Rp500.000 & 66,67 \\
\hline 9 & Petani Jagung & $\mathrm{Rp} 400.000$ & $\mathrm{Rp} 3.000 .000$ & 650,00 \\
\hline 10 & Petani Gula Aren & Rp1.500.000 & Rp5.800.000 & 286,67 \\
\hline 11 & Petani Gula Aren & Rp5 5.000 .000 & Rp9.000.000 & 80,00 \\
\hline 12 & Petani Gula Aren & Rp2.000.000 & Rp3.000.000 & 50,00 \\
\hline 13 & Petani Cabe & Rp1.300.000 & Rp2.800.000 & 115,38 \\
\hline 14 & Petani Cabe & Rp3.600.000 & Rp5.000.000 & 38,89 \\
\hline 15 & Petani Cabe & Rp1.000.000 & Rp5 5.000 .000 & 400,00 \\
\hline 16 & Petani Kelapa & Rp500.000 & Rp1.000.000 & 100,00 \\
\hline 17 & Petani Kelapa & Rp1.000.000 & Rp4.000.000 & 300,00 \\
\hline 18 & Petani Kelapa & Rp2.000.000 & Rp4.500.000 & 125,00 \\
\hline 19 & Petani Kelapa & Rp1.500.000 & $\operatorname{Rp} 3.500 .000$ & 133,33 \\
\hline 20 & Petani Cengkih & Rp200.000 & Rp500.000 & 150,00 \\
\hline 21 & Petani Kelapa & Rp1.000.000 & Rp4.000.000 & 300,00 \\
\hline 22 & Petani Kelapa & Rp2.000.000 & Rp4.000.000 & 100,00 \\
\hline 23 & Petani Kayu & Rp3.500.000 & Rp6.000.000 & 71,43 \\
\hline 24 & Wirausaha & Rp2.000.000 & Rp5.800.000 & 190,00 \\
\hline 25 & Wirausaha & Rp1.000.000 & Rp3.000.000 & 200,00 \\
\hline 26 & Wirausaha & Rp7.000.000 & Rp8.000.000 & 14,29 \\
\hline 27 & Wirausaha & Rp4.000.000 & Rp6.000.000 & 50,00 \\
\hline 28 & Wirausaha & Rp1.000.000 & Rp1.500.000 & 50,00 \\
\hline 29 & Wirausaha & Rp2.000.000 & Rp5.000.000 & 150,00 \\
\hline 30 & Wirausaha & Rp2.000.000 & $\operatorname{Rp} 5.000 .000$ & 150,00 \\
\hline
\end{tabular}

Tabel 4 menunjukkan masyarakat lingkungan Kalatin dengani jenis mata pencaharian yang mengalami peningkatan pendapatan, diantaranya Petani (petani yang tidak berpusat pada satu komoditi tanaman contohnya menanam cengkih, jagung, kelapa, maupun 
tanaman lain), Petani cengkih, Petani jagung, Petani kelapa, Petani cabe, Petani gula aren, Tukang Kayu (pengepul kayu dari daerahdaerah tertentu yang nantinya akan dijual kepada masyarakat sekitar sebagai bahan bangunan) setelah dilakukan pembangunan infrastruktur jalan bisa leluasa membeli dan mencari informasi untuk pembelian kayu didaerah lain, Tukang Pembuat Rumah Kayu (pengrajin khusus membangun rumah) dan Wirausaha (Masyarakat yang biasanya mengepul dan menjual hasil komoditi (berdagang) contohnya masyarakat membeli dan menjual kembali di daerah-daerah lain seperti di pasar Karombasan hingga keluar pulau (Sanger).

Pada Tabel 4 menunjukkan bahwa adanya kenaikan pendapatan masyarakat setelah pembangunan infrastruktur jalan sebanyak $14,29 \%-650 \%$ atau 6 kali lipat dari pendapatan pada saat jalan belum diperbaiki. Hal ini karena infrastruktur jalan mempermudah masyarakat terutama petani, tukang, dan wirausaha untuk mendistribusikan hasil komoditi yang akan dijual di daerah luar. Selain itu, pengembangan masyarakat melalui pembangunan infrastruktur jalan membantu masyarakat dalam melakukan kegiatan pertanian. Contohnya: sebelum pembangunan infrastuktur jalan, Petani belum membawa mobil masih memakai roda sapi atau motor. Setelah pembangunan infrastruktur jalan, masyarakat sudah bisa membawa mobil untuk mengangkut dan mendistribusikan hasil komoditi. Pemasaran hasil komoditi yang sebelumnya memakan waktu karena hanya memakai kendaraan seadanya, bisa menjadi cepat dengan adanya mobil. Begitupun pada mata pencaharian lainnya.

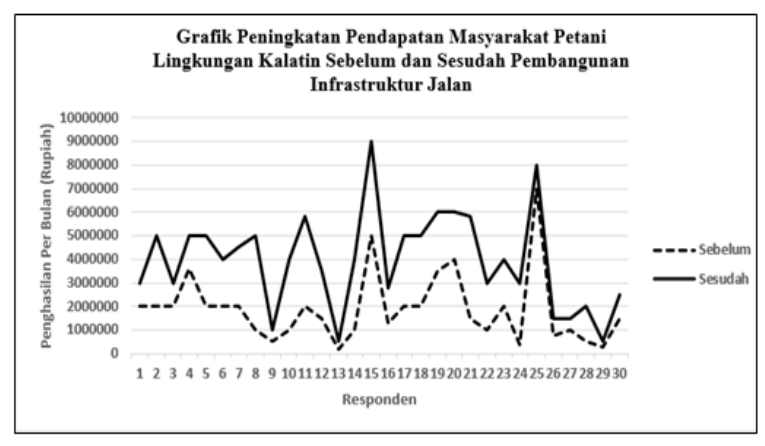

Gambar 1. Grafik Peningkatan Pendapatan Masyarakat Lingkungan Kalatin Sesudah Pembangunan Infrastruktur Jalan
Pada Gambar 1, menunjukkan bahwa terjadi peningkatan pendapatan masyarakat setelah dibangunnya infrastruktur jalan. Pembangunan infrastruktur jalan di Lingkungan Kalatin memberikan dampak peningkatan pendapatan sebesar $14 \%$ - $650 \%$ atau 6 kali lipat dari pendapatan sebelumnya, dihitung pada lampiran 2. Dengan demikian terbukti adanya pengaruh pembangunan infrastruktur jalan terhadap peningkatan pendapatan masyarakat. Hal ini karena prasarana jalan mempermudah akses dan aktivitas berdagang masyarakat baik dari petani maupun nonpetani (misalnya tukang dan wirausaha). Kendaraan yang bisa lewat sebelum pembangunan infrastruktur jalan yaitu motor (motor khusus jalan rusak), dan roda sapi. Sedangkan sesudah pembangunan infrastruktur jalan, sudah bisa dilewati mobil, roda sapi, motor, hingga mobil pick up. Hasilnya, masyarakat bisa lebih mudah memasarkan hasil komoditi diluar Lingkungan Kalatin. Selain itu, masyarkat belum mengetahui harga pasaran dari tiap komoditi sebelum pembuatan infrastruktur jalan. Setelah pembuatan infrastruktur jalan, masyarakat sudah bisa memasarkan komoditi diluar Lingkungan Kalatin dengan harga yang ada dipasaran, sehingga terjadi peningkatan pendapatan.

\section{Partisipasi Masyarakat Dalam Pembangunan Infrastruktur Jalan Di Lingkungan Kalatin}

Bentuk partisipasi merupakan cara yang efektif membangun kemampuan masyarakat untuk pengelolaan program pembangunan guna memenuhi kebutuhan lokal. Pengaruh bentuk partisipasi dari keterlibatan masyarakat dalam pemberdayaan masyarakat berupa perencanaan, pengambilan keputusan dan pelaksanaan. Dapat disimpulkan partisipasi masyarakat Lingkungan Kalatin berjalan dengan baik karena masyarakat turut melakukan bentuk partisipasi yang ada antar lain partisipasi berupa pelaksanaan.

Partisipasi dalam perencanaan yaitu partisipasi dalam pengembangan ide seseorang atau sekelompok orang turut memberikan saran 
atau ide-ide demi kebaikan pembangunan. Partisipasi ini merupakan tahap pertama dalam pembangunan. Masyarakat Lingkungaan Kalatin bersama pemerintah setempat telah mengadakan rapat guna kelancaran pembangunan infrastruktur jalan. Kemudian partisipasi dalam pengambilan keputusan dimana partisipasi masyarakat pada tahap ini sangat besar, terutama karena keputusan yang diambil menyangkut nasib mereka secara keseluruhan. Masyarakat Kelurahan Kalatin sudah melewati tahap ini dengan diskusi, sumbangan pemikiran, dan tanggapan. Selanjutnya partisipasi dalam pelaksanaan yang merupakan tindak lanjut dari tahap diatas. Dalam hal ini menegaskan bahwa partisipasi dalam pembangunan memberikan kontribusi guna menunjang pelaksanaan pembangunan yang berwujud tenaga, makanan/minuman, ataupun informasi yang berguna bagi pelaksanaan pembangunan. Partisipasi masyarakat Lingkungan Kalatin berwujud tenaga dan makanan/minuman dapat dilihat pada Tabel 5.

Tabel 5. Partisipasi Masyarakat Terhadap Pembangunan Infrastruktur

\begin{tabular}{llcccc}
\multicolumn{2}{c}{ Jalan } & & & \\
\hline \multirow{2}{*}{ No } & \multirow{2}{*}{ Partisipasi } & \multicolumn{2}{c}{$\begin{array}{c}\text { Jumlah Responden } \\
\text { (Orang) }\end{array}$} & Total & $\begin{array}{c}\text { Persentase } \\
(\%)\end{array}$ \\
\cline { 3 - 5 } & & Laki-laki & Perempuan & & \\
\hline 1 & Tenaga kejja & 14 & 4 & 18 & 60,00 \\
2 & $\begin{array}{l}\text { Makanan/minumsn } \\
\text { (logistic) }\end{array}$ & 0 & 12 & 12 & 40,00 \\
\hline & Jumlah Partisipan & 14 & 16 & 30 & 100,00 \\
\hline Sumber : Diolah Dari Data Primer, 2018 & & &
\end{tabular}

Berdasarkan Tabel 5, menunjukkan bahwa partisipasi masyarakat dalam bentuk tenaga kerja dan dalam bentuk makanan/ minuman (logistik) yang terdiri dari 16 Perempuan dan 14 laki-laki dengan jumlah partisipan keseluruhan adalah 30 orang. Masyarakat yang berpartisipasi sebagai tenaga kerja, diantaranya membantu pembuatan jalan dan masak-memasak serta membantu menyumbang makanan/minuman berupa kebutuhan pokok untuk konsumsi tenaga kerja.

Dari hasil tersebut, tingkat partisipasi masyarakat Lingkungan Kalatin dikatakan sangat berpengaruh dalam pembangunan infrastuktur jalan karena semua masyarakat di Lingkungan Kalatin ikut serta dalam pembangunan, baik tenaga maupun konsumsi.

\section{KESIMPULAN DAN SARAN}

\section{Kesimpulan}

1. Pemberdayaan masyarakat melalui partisipasi masyarakat dalam bekerja sama untuk melaksanakan pembangunan infrastruktur jalan di Lingkungan Kalatin dikatakan berjalan dengan baik karena masyarakat Lingkungan Kalatin melakukan bentuk partisipasi berupa pelaksanaan dalam bentuk tenaga dan makanan dan minuman.

2. Pembangunan infrastruktur jalan di Lingkungan Kalatin memberikan dampak peningkatan pendapatan sebesar 14,29\% $650 \%$ atau 6 kali lipat dari pendapatan pada saat jalan belum diperbaiki. Hal ini karena infrastruktur jalan mempermudah akses pemasaran hasil komoditi baik didalam maupun diluar daerah Lingkungan Kalatin.

\section{Saran}

1. Peranan Pemerintah terlebih khusus Kepala Desa terhadap pemberdayaan masyarakat khususnya dibidang pertanian serta pemeliharaan infrastruktur jalan di Lingkungan Kalatin, Kelurahaan Lowu Utara, Kecamatan Ratahan, Kabupaten Minahasa Tenggara hendaknya dilakukan secara konsisten dan berkesinambungan.

2. Selain penyuluhan dan pelatihan bagi warga masyarakat, pelatihan juga perlu diadakan bagi aparat desa guna meningkatkan SDM bagi warga desa.

\section{DAFTAR PUSTAKA}

Bumdes, 2017. Apa yang Dimaksud dengan Pemberdayaan Masyarakat Desa? http://bumdes .id /2017 /12/apa- yangdimaksud- dengan- pemberdayaanmasyarakat- desa- 11/ diakses 10 Oktober 2018. 
Oroh G. S. 2014. Peranan Pemerintah Desa dalam Pemberdayaan Masyarakat di Bidang Pertanian di Desa Tumaratas Kecamatan Langowan Barat Kabupaten Minahasa Jurnal Ilmu Politik. 1-11, Manado.
Senoaji G. 2011. Kondisi Sosial Ekonomi Masyarakat Sekitar Hutan Lindung Bukit Daun di Bengkulu. Fakultas Pertanian Universitas Bengkulu, Bengkulu. 